Historic, Archive Document

Do not assume content reflects current scientific knowledge, policies, or practices. 



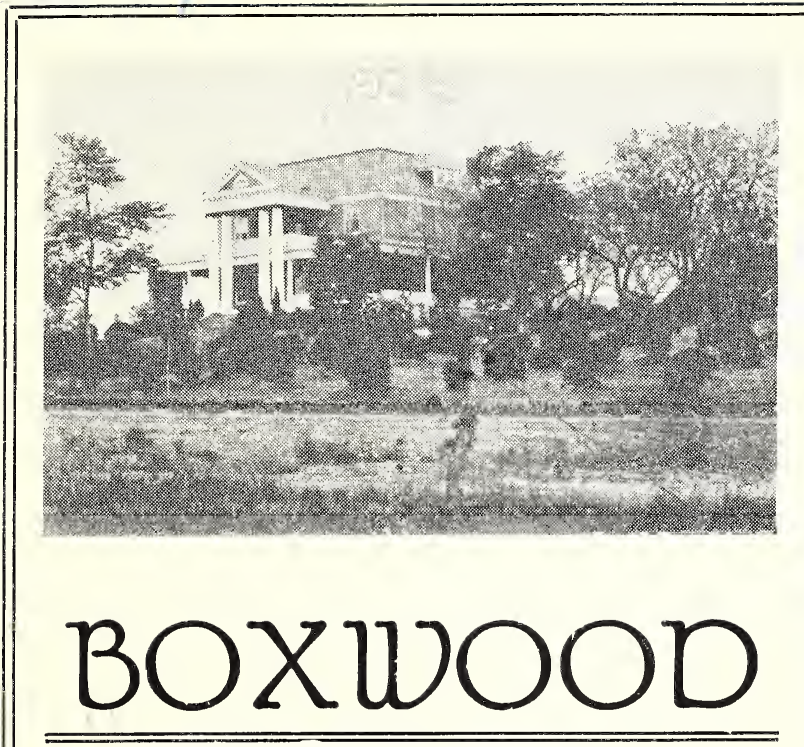

䇺

A Presentation

by

Royal Oak Boxwood Farms Marion _. Virginia

$\infty 000$

New York City Warehouse 460 Eleventh Avenue

Longacre 5663

Between 37th-38th Streets

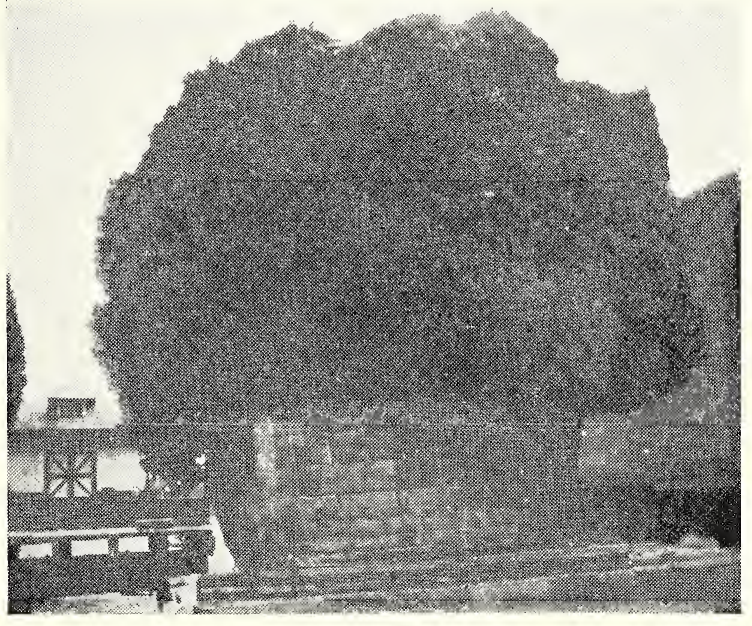




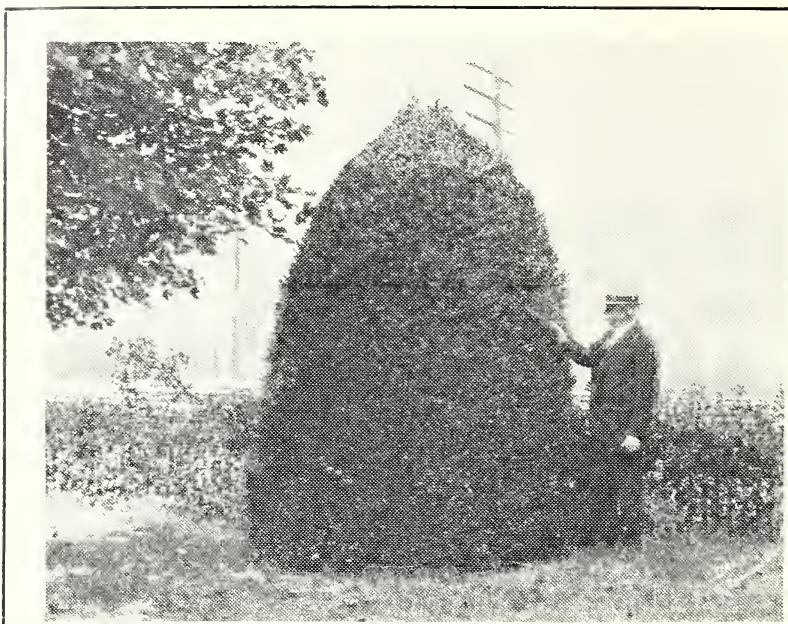

\section{An Investment}

D OYAL OAK BOXWOOD for your garden or es1 tate is an investment. Here on our Virginia farms, carefully nurtured and handled, we offer to the present day lover of the beautiful in landscape a real Colonial treasure. Through centuries these evergreens have stood as the supreme embodiment of the elite of the family. Through the centuries they have had their praises sung in song and in story, and he who today continues to preserve the boxwood of romance days, has a heritage in his estate that in passing on, can never be duplicated.

The Royal Oak Boxwood can be seen by appointment by calling Longacre 5663 , or at our warehouses and offices 460 Eleventh Averiue.

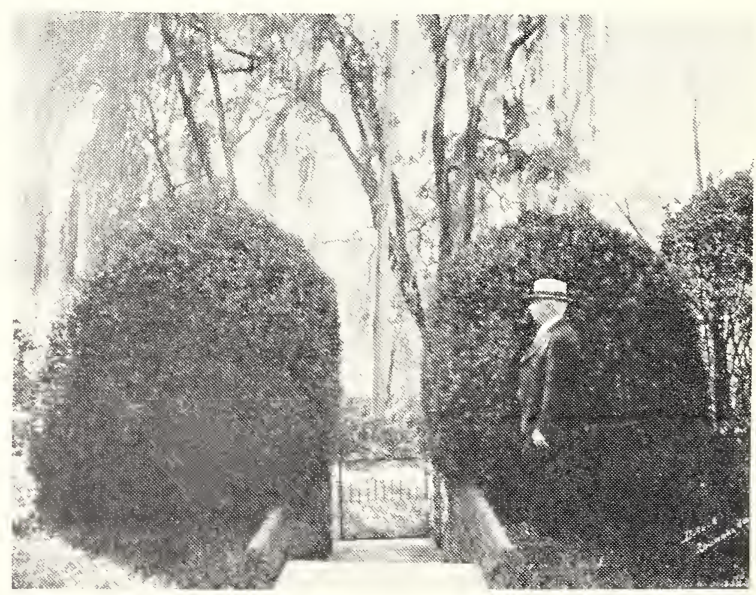

